\title{
Chapter 15 \\ Learning Networks Among Swedish \\ Municipalities: Is Sweden a Small World?
}

\author{
Christopher Ansell, Martin Lundin, and Per Ola Öberg
}

Distributed, networked learning processes are widely touted as a basis for superior performance. Public and private organizations, cities and regions, and even nations are exhorted to network, to innovate collaboratively, to benchmark, and above all to learn from one another (Agranoff, 2006; Betsill \& Bulkeley, 2004; Cooke \& Morgan, 1993; Goldsmith \& Eggers, 2004; Kraatz, 1998; Lee \& van de Meene, 2012; Powell, Koput, \& Smith-Doerr, 1996; Slaughter, 2009). From case study research, we know a good deal about local strategies of networking, innovation, and collaboration (e.g., Saxenian, 1996). And from diffusion studies, we also know that the structure of networks shapes the diffusion of information, ideas, innovations, policies, and best practices (Cao, 2010; Davis, 1991; Granovetter, 1973; Gray, 1973; Hedström, Sandell, \& Stern, 2000; Lee \& Strang, 2006; Mintrom \& Vergari, 1998; Stone, 2004). However, we know relatively little about how the local learning choices of individuals, firms, cities, or nations aggregate into global network patterns that may subsequently affect diffusion. In this chapter, we explore this question by examining how the learning strategies of Swedish municipalities aggregate to produce a national intermunicipal learning network.

Interdependence between the policy choices of local governments has attracted growing interest recently (Lee \& van de Meene, 2012; Marsden, Frick, May, \& Deakin, 2011). It has been argued that subnational governments can act like demo-

\footnotetext{
C. Ansell $(\bowtie)$

Charles and Louise Travers Department of Political Science, University of California,

Berkeley, CA, USA

e-mail: cansell@berkeley.edu

M. Lundin

Institute for Evaluation of Labour Market and Education Policy (IFAU), Uppsala, Sweden

e-mail: martin.lundin@ifau.uu.se

P.O. Öberg

Department of Government, Uppsala University, Uppsala, Sweden

e-mail: PerOla.Oberg@statsvet.uu.se
} 
cratic laboratories (Shipan \& Volden, 2012; Volden, 2006) and that they can learn important lessons from each other. Literature on urban policy mobilities (Jacobs, 2012; McCann, 2011) and policy diffusion (Krause, 2011; Lee \& van de Meene, 2012) has begun to explore the mechanisms of policy transfer and diffusion between cities. Our research shares this interest in policy mobility and diffusion but approaches the issue from a different angle. Rather than asking why a policy moves from city A to city $\mathrm{B}$, our research is interested in uncovering the relational principles that constitute interurban networks in the first place. We approach the issue from this angle, in part, because of the character of our data, which does not enable us to track the mobility or diffusion of specific policies, but does give us an unusually detailed look at the relationships of learning between Swedish municipalities. Our contribution is therefore not to explain mobility or diffusion per se, but rather to utilize social network analysis to uncover the structuring principles of national learning networks.

Over the last decade or so, economic geographers and economic sociologists have been engaged in a similar exploration of the relational principles that guide learning in interfirm networks. Their research has shown that interfirm learning is often structured by geographical proximity, but that nonlocal networks may be critical pipelines that move knowledge between local clusters of firms (e.g., Amin \& Cohendet, 1999; Bathelt, Malmberg, \& Maskell, 2004; Bell \& Zaheer, 2007; Glückler, 2013; Owen-Smith \& Powell, 2004). Although geographical proximity is understood to enhance interactional learning, nonlocal networks are increasingly understood to be important for preventing local learning networks from becoming too parochial (Boschma, 2005; Maskell, 2014). Although research is beginning to reveal variations on this theme, this literature valuably highlights the composite character of learning ecologies, which are produced through the interplay of geography and networks. Our research builds on this literature, but extends this discussion from firms to municipalities. Our research therefore offers a bridge between this literature on interfirm learning and the literature on policy mobility and diffusion. To our knowledge, there has been little cross-fertilization between these two important bodies of literature.

Our exploration of intermunicipal learning networks is based on a unique survey of municipal civil servants conducted in 2010 as part of a wider study of municipal knowledge use in Sweden. In this survey, the senior civil servants in all Swedish municipalities were asked to name other Swedish municipalities from whom they had drawn lessons in a given period. When these choices are aggregated across all Swedish municipalities, the result is a unique glimpse into what an intermunicipal learning network looks like on a national scale. Swedish municipalities provide an interesting context in which to examine learning networks. Much of the fabled Swedish welfare state is actually administered by Sweden's 290 municipalities varying in size from roughly 3000 inhabitants to 750,000 inhabitants. ${ }^{1}$ These municipalities have responsibility for a wide range of policy areas, including social ser-

\footnotetext{
${ }^{1}$ Prior research notes significant variation in welfare services across municipalities, leading some scholars to describe Sweden as a multitude of "welfare municipalities" (Trydegård \& Thorslund, 2010).
} 
vices, education, daycare, environmental protection, and planning, and municipal employees compose approximately $25 \%$ of the Swedish workforce (Sveriges Kommuner och Landting, 2014). Although they are organized into 21 counties, the county-municipality relationship is not a hierarchical one and while Swedish municipalities operate within a framework of national law, they have considerable latitude about how to organize and deliver government services and regulation. ${ }^{2}$ Thus, their extensive and parallel responsibilities create powerful incentives to learn from one another, but their political autonomy means that they are relatively free to decide whom to learn from. We know that the Swedish Association of Local Authorities and Regions (SALAR) actively encourages the municipalities to learn from each other, but we do not know how their choice of whom to learn from aggregates to produce a national learning network.

The chapter is organized as follows: The first section describes our data. In the second section, we provide some basic information about the extent of learning among municipalities and about how municipalities try to learn from each other. In section three, we use social network analysis to explore how municipal clusters of learning are structured. Then, in section four, we examine whether the Swedish municipalities can be described as a small world through which ideas and information may easily diffuse. Section five focuses on what characterizes the municipalities whose nonlocal networks bridge between otherwise disconnected municipalities in the learning network. Section six concludes.

\section{Data}

Our data come from a survey of Swedish municipalities conducted in 2010. The survey asked a range of questions about knowledge use in each municipality and was answered by the top civil servant. This manager is in charge of the office responsible for preparing policy proposals for the municipal executive board, which is the most important and powerful local government institution in Sweden (Bäck, 2005). Composed of local politicians appointed in proportion to their party mandate in the municipal assembly, these boards have responsibility for managing and coordinating local administration and also have financial responsibility for the municipality.

The key variable of this study is learning or lesson-drawing (Freeman, 2008, p. 376; see also, Lundin, Öberg, \& Josefsson, 2015). Learning is a voluntary activity involving a search for knowledge in order to solve problems. That is, in a learning process actors try to improve the understanding of the relationship between cause and effect by taking advantage of others' experiences (Lee \& Strang, 2006;

\footnotetext{
${ }^{2}$ In a comparative perspective, Swedish local governments are considered to have a lot of power (Sellers \& Lidström, 2007). Municipalities have taxing power and a constitutionally protected right of self-government. Swedish public agencies are also known to actively support innovation. The 2010 European Innobarometer Survey found that innovation in the Swedish public sector is much more bottom-up (initiated internally) rather than driven by policy mandate (Arundel \& Hollanders, 2011).
} 
Lee \& van de Meene, 2012; Meseguer, 2005). The survey question used to elicit the municipal learning network was: "What other municipalities have you drawn important lessons from within your field during the last election period (since January 2007)?" In response, municipal managers could mention as many other municipalities as they liked.

A web survey was distributed as a first step, with three follow-up reminders. We then distributed a somewhat shorter version as a postal survey in a second step. This led to a response rate of $78 \%$. The remaining nonrespondents were telephoned, producing a $100 \%$ response rate on the learning question. ${ }^{3}$

The information that can be spread among municipal head managers is of a diverse character because a wide range of policy decisions are handled in the municipal executive boards. Overarching issues like budgets, policies, programs, guidelines, and various action plans (e.g., wind power plans and school plans) are within the managers' purview. Somewhat more limited decisions are also frequently made, such as whether to shut down a certain school or where to locate a recycling station. Moreover, the committees handle minor issues such as what documents should be archived and for how long. We do not know exactly what issues respondents had in mind when answering our question, but they all have equivalent positions within the municipalities and were asked about lessons learned within their field, which includes all issues handled by the municipal executive boards. Furthermore, they were explicitly told to ignore issues that do not reach the political level and "routine matters" concerning individual citizens.

In addition to the key question, we use some other questions from the survey in order to describe learning processes in Swedish municipalities in more detail. Moreover, a series of interviews with municipal officials was conducted in order to develop a more qualitative understanding of how municipalities use knowledge to make policy decisions. Semistructured, open-ended interviews were conducted with 40 politicians and civil servants in six municipalities. These municipalities were strategically selected to maximize variation (two large, two medium-sized, and two small municipalities). For each pair, one municipality had a stable social democratic majority and the other had shifting majorities. The interviews lasted from 45 to 90 min and were recorded. Although we do not report systematically on these interviews in this chapter, they do provide some background information for our interpretation of learning networks.

\section{Local Learning Through Informal Personal Connections}

A first step in the analysis is to explore how important information from other municipalities is in municipal decision-making. We also want to know what channels are used to collect information. Table 15.1 provides some basic statistics on

\footnotetext{
${ }^{3}$ Note that the other survey questions presented in this chapter are based on a somewhat smaller sample (i.e., about $78 \%$ of the population).
} 
Table 15.1 Learning among Swedish local governments: Various survey responses

\begin{tabular}{|c|c|c|c|c|}
\hline \multicolumn{2}{|c|}{$\begin{array}{l}\text { Q1. How many other } \\
\text { municipalities have been } \\
\text { learned from? ("Outdegree") }\end{array}$} & \multicolumn{3}{|c|}{$\begin{array}{l}\text { Q2. How often is information from (a) other municipalities } \\
\text { (b) SALAR used when issues are prepared before political } \\
\text { decision? }\end{array}$} \\
\hline $\begin{array}{l}\text { Number of municipalities } \\
\text { mentioned }\end{array}$ & $\%$ & $\begin{array}{l}\text { Response } \\
\text { alternative }\end{array}$ & Other municipalities (\%) & $\operatorname{SALAR}(\%)$ \\
\hline 0 & 8 & $\begin{array}{l}\text { Never or almost } \\
\text { never }\end{array}$ & 12 & 2 \\
\hline 1 & 5 & $\begin{array}{l}\text { Less than half of } \\
\text { the issues }\end{array}$ & 54 & 39 \\
\hline $2-5$ & 39 & $\begin{array}{l}\text { About half of the } \\
\text { issues }\end{array}$ & 21 & 30 \\
\hline $6-9$ & 22 & $\begin{array}{l}\text { More than half of } \\
\text { the issues }\end{array}$ & 12 & 20 \\
\hline $10-15$ & 19 & $\begin{array}{l}\text { Always or almost } \\
\text { always }\end{array}$ & 1 & 9 \\
\hline $16-26$ & 7 & & & \\
\hline \multicolumn{5}{|c|}{ Average: 6.86} \\
\hline \multicolumn{5}{|c|}{$\begin{array}{l}\text { Q3. Channels used "often" or "very often" in order to get information about activities in other } \\
\text { municipalities? }\end{array}$} \\
\hline Channel & $\%$ & & Channel & $\%$ \\
\hline $\begin{array}{l}\text { 1. Informal personal } \\
\text { connections }\end{array}$ & 81 & & $\begin{array}{l}\text { 5. Conferences, seminars } \\
\text { etc. }\end{array}$ & 28 \\
\hline 2. Internet homepages & 72 & & $\begin{array}{l}\text { 6. Written reports } \\
\text { produced by other } \\
\text { municipalities }\end{array}$ & 21 \\
\hline $\begin{array}{l}\text { 3. Regular meetings with } \\
\text { certain municipalities }\end{array}$ & 67 & & 7. Information in media & 20 \\
\hline $\begin{array}{l}\text { 4. Written reports } \\
\text { produced by SALAR }\end{array}$ & 65 & & 8. Official visits & 19 \\
\hline
\end{tabular}

learning among municipalities in Sweden according to the survey responses. Of the 290 municipalities surveyed, only $8 \%$ reported they had not learned something important from another municipality during the previous 4 years (since the last election period), whereas $61 \%$ reported learning from between two and nine other municipalities, and the maximum number reported was 26 other municipalities. On average, the municipal managers report that their municipality draws important lessons from about seven other municipalities.

The survey also included a question on how often information from other municipalities is used when issues are prepared before political decision. Table 15.1 reveals that although information from other municipalities is not used in a majority of issues, only $12 \%$ reported that they "never or almost never" use such input in the policy process. Furthermore, we asked how often information produced by the Swedish Association of Local Authorities and Regions (SALAR) is employed in the policy process. Around two percent claim that they "never or almost never" use information from SALAR, whereas $59 \%$ use information from SALAR in at least 
half of the issues. Thus, SALAR seems to function as an important bridge between local governments. This finding was reinforced in the in-depth interviews.

Table 15.1 verifies another conclusion drawn from the in-depth interviews: informal personal connections are the most important channel used to get information about activities in other municipalities. Other important channels include the internet homepages of other municipalities, regular meetings and written reports where SALAR describes various activities at the local level.

\section{Learning Clusters Are Based on County Structure}

In an analysis of dyads of municipalities by Lundin et al. (2015) using the same data analyzed in this chapter, it is demonstrated that Swedish municipalities primarily learn from their local neighbors. ${ }^{4}$ The analysis reveals that geographic proximity greatly increases the probability that a municipality will learn from another municipality. For instance, if two municipalities are located in the same county, the predicted probability that a learning link will be established is .054 , all else being equal. If the municipalities are not located in the same county, the probability is only .003. Our interviews point in the same direction. As one local civil servant told us:

Above all, it is if you find somebody that is successful in a certain area, somebody that has given thought to something. Primarily it is often among neighbors that we look because they are quite similar and work under roughly the same conditions. (2011 interview with civil servant)

The importance of geographical proximity suggests that municipal learning networks in Sweden might be very parochial. If so, it is reasonable to expect that new knowledge, ideas, and best practices would be quite slow to diffuse to local governments in Sweden. But the dyadic analysis presented above does not account for the possibility of learning indirectly through less proximate networks. To explore this possibility, we employ ideas from social network analysis. The aim is to deepen our understanding of the clustering properties of a potential learning network: How are clusters structured? To find out more about this, we started by using the GirvanNewman method of detecting community structure (Girvan \& Newman, 2002). This method finds clusters by iteratively removing edges with high edge betweenness scores until it reaches some specified minimum number of clusters. A betweenness score summarizes the number of times an actor is a bridge between two other actors in the network (Freeman, 1977).

The analysis is presented in Table 15.2 and it reinforces findings in Lundin et al. (2015): county is a very strong predictor of cluster membership. There are 21 counties in Sweden and when directed to detect 21 clusters, the community structure

\footnotetext{
${ }^{4}$ The main research question in Lundin et al. (2015) is whether local governments tend to learn from governments that are more successful than others; the empirical findings support this hypothesis. However, the importance of proximity, similarity, and power is also examined in the study.
} 
Table 15.2 Girvan-newman clusters by county

\begin{tabular}{lll}
\hline $\begin{array}{l}\text { Cluster } \\
\text { number }\end{array}$ & Counties (number of municipalities per county) & \\
\hline 1 & Stockholm (26); Södermanland (1); Skåne (1) & E-I index \\
2 & Södermanland (7); Uppsala (2) & -0.411 \\
3 & Gävleborg (10); Västernorrland (4); Uppsala (1) & 0.000 \\
4 & Västmanland (7); Uppsala (4); Södermanland (1); Gotland (1); & -0.310 \\
& Örebro (1) & 0.162 \\
5 & Östergötland (12); Halland (1) & -0.197 \\
6 & Västra Götland (22); Östergötland (1); Jönköping (1) & -0.338 \\
7 & Jönköping (12); Halland (4); Blekinge (1) & -0.116 \\
8 & Kronoberg (8) & -0.195 \\
9 & Kalmar (12) & -0.417 \\
10 & Blekinge (4) & 0.130 \\
11 & Skåne (16) & -0.452 \\
12 & Skåne (12) & -0.282 \\
13 & Jämtland (8); Skåne (1); Västernorrland (1) & -0.020 \\
14 & Skåne (1) & 0.000 \\
15 & Västra Götaland (11); Halland (1) & -0.416 \\
16 & Västra Götaland (14) & 0.262 \\
17 & Västerbotten (15); Västmanland (1); Västra Götaland (1); & -0.371 \\
& Västernorrland (1); Norbotten (1) & \\
18 & Värmland (16) & -0.247 \\
19 & Örebro (11) & -0.426 \\
20 & Dalarna (14); Västmanland (2) & -0.229 \\
21 & Norrbotten (13); Västernorrland (1) & -0.277 \\
\hline
\end{tabular}

identified by the Girvan-Newman method is very close to the structure of counties. Although some clusters contain municipalities from more than one county, the county structure is clear. Twenty of the clusters are dominated by municipalities from a single county (cluster 14 is an exception with only one municipality). Municipalities from some counties are divided between clusters (Västra Götaland, Skåne), but a single county still dominates each cluster. Only a few counties have the municipalities distributed across clusters without clearly dominating at least one cluster (Uppsala, Västernorrland). The county structure of clusters remains robust even if the algorithm is told to produce a different number of clusters. ${ }^{5}$

We can also look at what is called the E-I index for each of these clusters. The E-I index is a measure that varies between -1 and +1 . At +1 , all ties are external to

\footnotetext{
${ }^{5}$ With 10 clusters, the method identifies a regional organization that resembles the three old Swedish provinces (Norrland, Svealand, and Götaland). However, municipalities still tend to cluster with other municipalities from their own county. The northern region includes Norrbotten, Västerbotten, and Västernorrland. The center region includes Stockholm, Uppsala, Södermanland, Gävleborg, Dalarna, Västmanland, Gotland, and Jämtland. Then there are seven small regions in the south: (1) Västra Götaland, Halland, and Jönköping; (2) Örebro; (3) Östergötland; (4) Kronoberg and Blekinge; (5) Värmland; (6) Kalmar; and (7) Skåne.
} 
a group (in this case the cluster); at -1 , all ties are internal to the group. ${ }^{6}$ We can see in Table 15.2 that a large majority of the E-I indexes for the clusters are negative. These findings suggest that learning within clusters is much stronger than more global learning.

Because the pattern of emergence of the global network works via a principle of local proximity, we might expect local clusters to cluster together on a geographical basis. In other words, we should expect the clusters identified above to cluster into larger regions. To examine this, we wanted a clustering technique that did not require us to assign the number of clusters. We selected Markov clustering, which uses a different strategy of community detection (van Dongen, 2008). The GirvanNewman community detection procedure used above identifies community structure by removing edges with high betweenness centrality until nonoverlapping groups appear. Markov clustering identifies community clusters by "walking around"; it identifies clusters as places where the algorithm spends a lot of time walking. This strategy intuitively captures the way information might circulate geographically.

The Markov clustering identified 22 clusters, which at first glance might seem to approximate the county structure of Sweden. However, two of these clusters are very large and many others are quite small. Our interpretation is that the Markov clustering algorithm identifies the regional as opposed to the local clustering structure of the network. These larger regional clusters attracted our attention because they suggest that one of the ways the national learning network might be integrated is through larger learning regions. These regional clusters could be significant in the circulation of knowledge among Swedish municipalities. A study of regional innovation and networks by Fleming, King, and Juda (2007), for example, found that such large components are positively correlated with innovation in patent co-authorship networks.

The two large clusters are indeed regions in a spatial sense. One of them (Fig. 15.1) represents the northern coast plus the Stockholm region (minus Stockholm itself). The second region (Fig. 15.2) runs spatially east to west in the southern part of Sweden and contains the Göteborg region. We also observe that a distinctive subregion can be detected in the Southern region (Fig. 15.2). This subregion is an extremely tight cluster of municipalities around the city of Göteborg. A possible explanation for this tight clustering is the formal creation of a metropolitan region. The formal association is called the Göteborg Region Association of Local Authorities, and the member municipalities are Ale, Alingsås, Göteborg, Härryda, Kungsbacka, Kungälv, Lerum, Lilla Edet, Mölndal, Partille, Stenungsund, Tjörn, and Öckerö. All these belong to the distinctive subregion visually detected in Fig. 15.2.

The West Sweden region (Västra Götalandsregionen) that includes the Göteborg Region Association of Local Authorities has been studied in prior research. Gren (2002) notes that this is one of the best organized regions in Sweden, partly through

\footnotetext{
${ }^{6}$ The E-I index for all the municipalities using this clustering was -.271 (the expected E-I index was .893 , significant at $<.05$ ).
} 


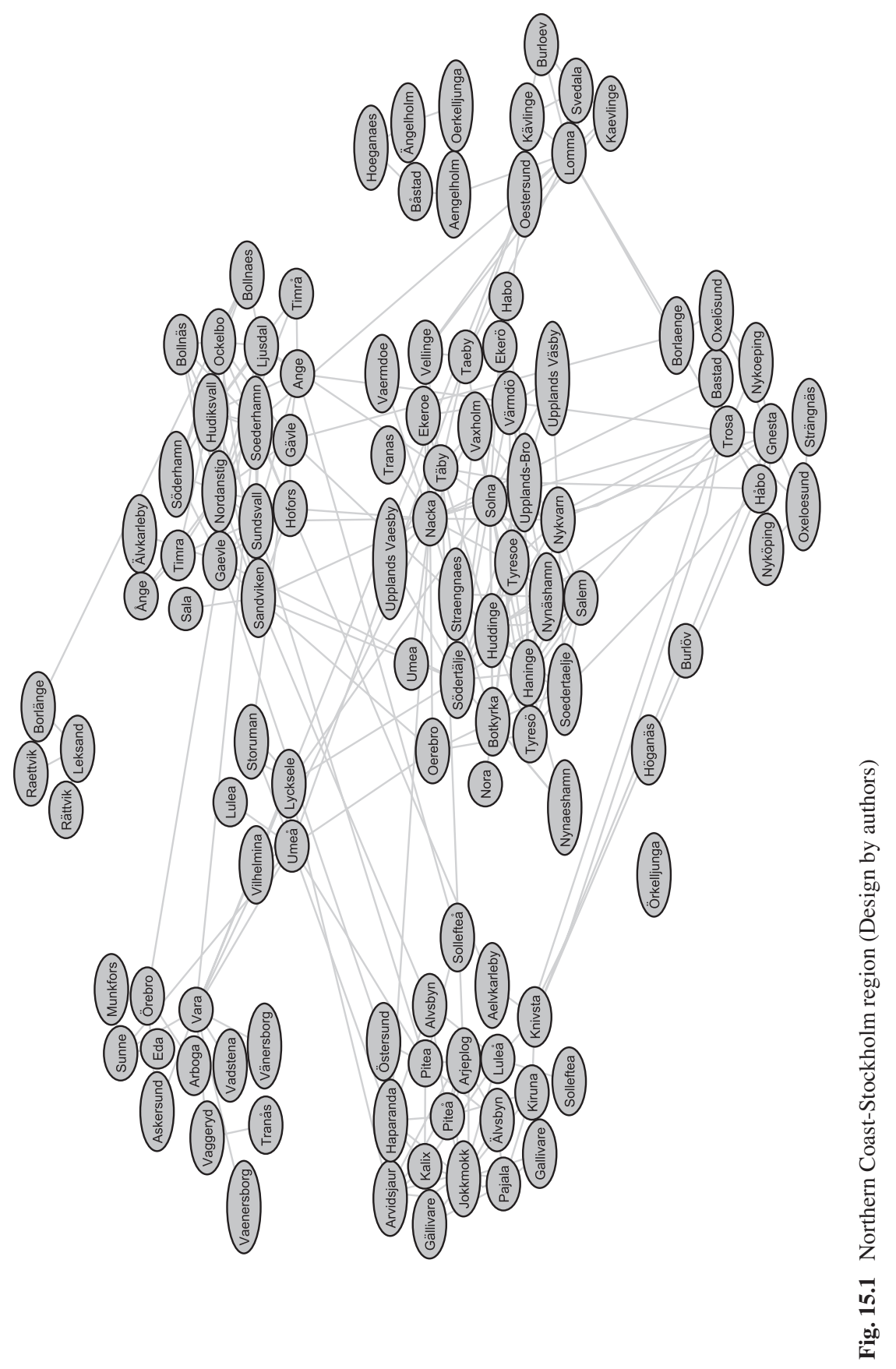




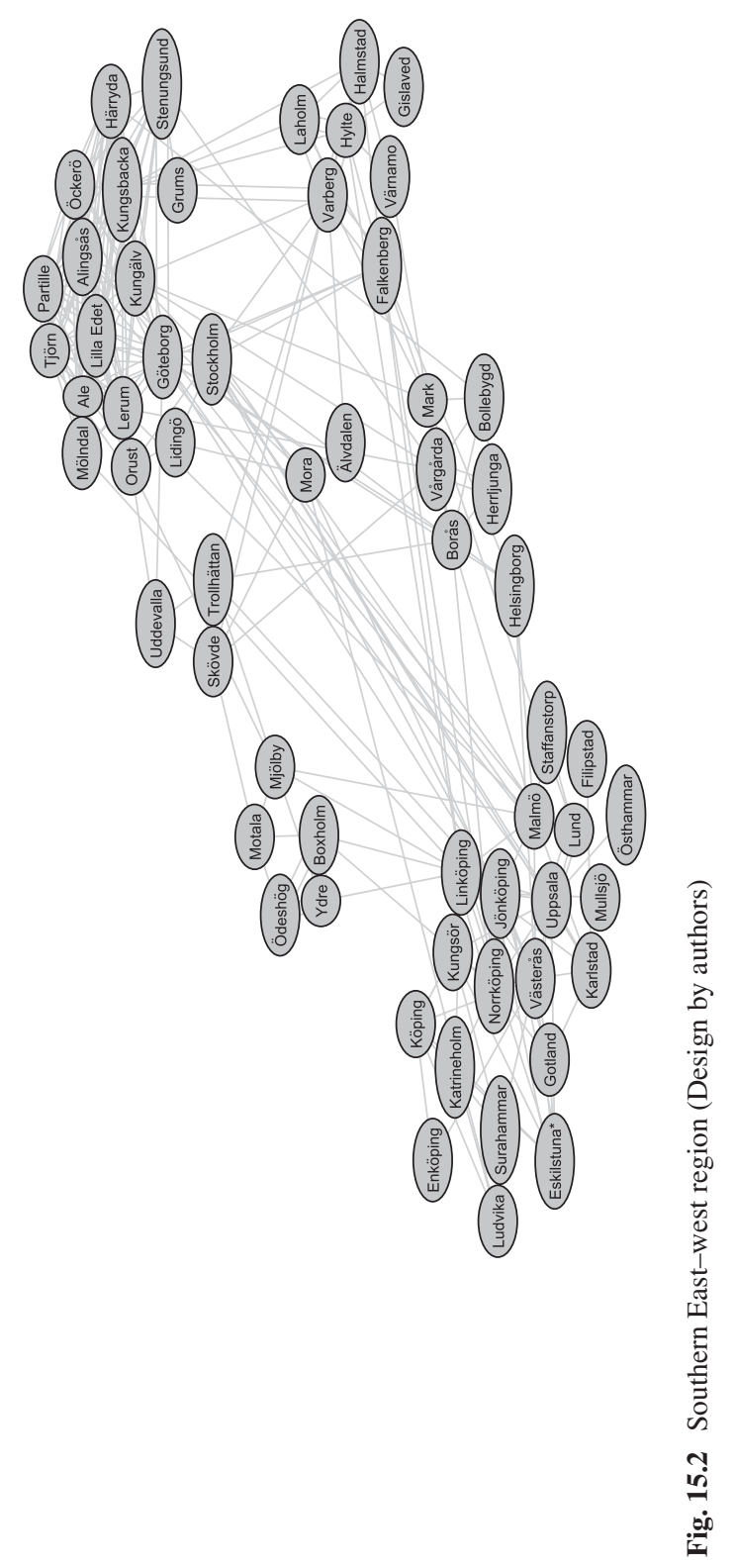


support from the European Union. Lidström (2011) found that citizens in the municipal regions of Göteborg (13 municipalities) and Umeå (6 municipalities) adopted more of a city-regionalist attitude (emphasizing the importance of intermunicipal coordination on a regional basis), as opposed to a localist attitude (strong municipal autonomy). The findings of Gren (2002) and Lidström (2011) suggest explanations for the existence of this subregion in the learning network.

\section{A Small World?}

The previous analysis has shown that learning networks in Sweden are to a large extent structured by county. However, we want to know more about whether the municipalities are efficiently integrated on a national scale. The literature on smallworld networks suggests that networks might be well connected despite highly localizing tendencies (Watts, 1999; Uzzi, Amaral, \& Reed-Tsochas, 2007). Smallworld networks are more cosmopolitan than expected because of the connections that occur among local clusters. If Swedish municipalities compose a small world, knowledge, ideas, and best practices might be diffused widely and rapidly despite the localism of learning networks.

A small-world network is defined as a graph with high clustering but low path length. ${ }^{7}$ A random graph typically has low clustering but also short average path lengths. A highly clustered network, by contrast, generally has high path lengths. A small-world network is a network with higher clustering than a random graph but with similar path lengths. A key feature of a small-world network is that despite the high clustering, which is expected to impede communication across the network, links between clusters can greatly shorten the path lengths and hence facilitate more rapid and cosmopolitan communication. In small worlds, path lengths are often reduced through the influence of highly connected hubs that link different clusters together. Well-connected hubs are not a necessary feature of small worlds, but it is reasonable to expect them to be important in networks with high local clustering. A number of scholars have pointed to the potential for small-world networks to diffuse knowledge and enhance innovation. Cowan and Jonard (2004), for example, simulated knowledge diffusion in innovation networks and found that diffusion in smallworld networks produces higher knowledge levels (in the network as a whole) than either a more local network or a random network.

Two measures have been used to identify whether a network exhibits smallworld properties: a clustering coefficient (as defined by Watts, 1999; labeled $c c$ for

\footnotetext{
${ }^{7}$ Clustering refers to the density of interconnections in each social network actor's local neighborhood - the set of other actors with whom the focal actor is directly connected. The overall clustering of a network is the mean clustering across all the actors in the network. Path length is the mean number of steps it takes each actor in the network to reach every other actor in the network when taking the shortest path.
} 
Table 15.3 Clustering and average path length in municipal learning networks in Sweden

\begin{tabular}{lcc}
\hline & Sweden & Random \\
\hline Clustering $(c c)$ & 0.293 & 0.025 \\
Length $(L)$ & 5.080 & 3.215 \\
\hline
\end{tabular}

clustering coefficient) and a measure of average path length (labeled $L$ ). ${ }^{8}$ These measures are then compared to a random graph of the same size and density (an Erdos-Renyi random graph). Table 15.3 shows the basic measures in the Swedish case.

In comparing the results in Table 15.3, we see that the Swedish local learning network is much more clustered than the random graph, but the path lengths are also longer. We can take this a step farther by estimating the small-world quotient (Q), which is given by Eq. [15.1]:

$$
Q=\frac{c c_{\text {Sweden }}}{c c_{\text {Random }}} / \frac{L_{\text {Sweden }}}{L_{\text {random }}}
$$

A small world is usually defined as having a quotient greater than 1 . In this case, the result is: $11.72 / 1.58=7.44$. So by this standard, the learning network of Swedish municipalities is indeed a small world, though the path lengths are a little high. The higher path lengths might indicate there are fewer hubs in the Swedish network than in an ideal small world.

\section{Learning Hubs}

As noted above, hubs are important in small-world networks because their more cosmopolitan ties allow information to widely and rapidly diffuse. Amin and Cohendet (1999) claim that nonlocal networks are particularly crucial for pathbreaking innovation, whereas local networking results in more incremental innovation. Thus, hubs are expected to fulfill a crucial role in the diffusion of innovations

\footnotetext{
${ }^{8}$ The clustering coefficient $(c c)$ is measured using the clustering coefficient algorithm in UCINET VI (there are various versions of $c c$; UCINET uses Watts's version; see, Watts, 1999). The algorithm produces both a weighted and an unweighted coefficient. The unweighted coefficient was used here. (There is a discussion in the literature about the tradeoffs between the two. But it does not make too much difference in this case because the results are similar. The weighted $c c$ is slightly lower than the unweighted $c c$ for the Swedish network; for the random network, weighted and unweighted $c c$ 's are the same). Path length is measured using the geodesic distance algorithm in UCINET VI, which produces a matrix of shortest path lengths between nodes. UCINET VI's univariate statistics algorithm then calculates mean path length. To produce the Erdos-Renyi random graph, the random graph algorithm in UCINET VI (subcommand Erdos-Renyi) is used, specifying that the graph should be same size and density as the Swedish network - 290-x290;.0237 density).
} 
Table 15.4 Correlation between Hub measures

\begin{tabular}{lrrr}
\hline & Hub A & Hub B & Hub C \\
\hline Hub A & 1.00 & & \\
Hub B & .56 & 1.00 & \\
Hub C & .78 & .43 & 1.00 \\
\hline
\end{tabular}

among the clusters. Accordingly, identifying the hubs and finding out what characterizes these municipalities is important.

We devised three ways to measure the extent to which each municipality can be characterized as a learning hub. Based on our view that hubs are transit points for learning, hubs should not only be learned from, but they must also learn from others. They should stand out from other municipalities in this respect. Our first measure is based on degree centrality, which captures the local connectedness of a municipality. By multiplying together how many other municipalities reported learning from a municipality (indegree) by how many others that municipality learned from (outdegree), we get a simple variable capturing the extent to which a municipality takes on the role as a transit point in the Swedish municipal learning network (Hub A).

One problem with this measure is that it does not take indirect ties into account. Potentially, a municipality can have high indegree and high outdegree without being that well connected to distant (in network terms) municipalities. Another approach is therefore to use the concept of closeness centrality developed by Valente and Foreman (1998). Valente and Foreman distinguish two measures, integration and radiality. Integration is a measure of how closely other actors in the network are connected to you via a chain of contacts; a municipality is more integrated if other municipalities must take fewer steps (path lengths) to reach you. Radiality is a measure of how well you are connected outwards to others - that is, how easily you can reach others through direct or indirect networks. These measures go beyond a local measure of degree centrality by incorporating the indirect links to the entire network. ${ }^{9}$ By multiplying integration and radiality we get a second hub measure (Hub B).

A third possible measure (Hub C) is betweenness centrality (Freeman, 1977), that is, the number of times a municipality sits on the shortest possible path between all other municipalities in the network. Actors with high betweenness scores may perform brokering roles by connecting otherwise disconnected actors and clusters.

Table 15.4 shows positive correlation coefficients between the three hub measures. The correlations are not exceptionally strong, which suggests that they capture somewhat different dimensions of what it means to be a hub. Beyond suggestive interpretations, theoretical arguments for why one of these hub measures might be

\footnotetext{
${ }^{9}$ The Valente-Foreman measures use the reverse of the average distances between nodes. The reversed distance is the diameter minus the geodesic distance. The diameter is the longest path between any two points, whereas the geodesic distance is the shortest path. Basically, they reverse the distance measure, turning it into a closeness measure.
} 
better than the others are not well articulated in the small-world literature. We therefore approach hub identification ecumenically by looking for municipalities that score well on all three measures.

To get a sense of how well hubs are spread out geographically, Fig. 15.3 depicts the percentage of municipalities over the 75th percentile on each hub measure within each county. The pattern is quite robust to the selection of measure, although there is some obvious variation. Västra Götland and Halland, two neighboring counties in western Sweden, have a substantially larger share of cosmopolitan municipalities than other counties. At the other extreme, we find Gotland and Kronoberg. In most other counties, around $10-30 \%$ of the municipalities have a clear transit point character. Overall, the impression is that the hubs are fairly evenly distributed geographically, but that some counties depart from this general pattern.

Above, in Fig. 15.2, we discovered a tight network in western Sweden consisting of the members of the Göteborg Region Association of Local Authorities. Many of the municipalities belonging to this association also score high on the three hub measures. If we once again use the 75th percentile to separate out more cosmopolitan cities, $54 \%$ of the Associations' members are hubs if we focus on the most basic hub measure (Hub A). Using the other two hub measures yields $85 \%$ (Hub B) and $31 \%$ (Hub C), respectively. ${ }^{10}$ At first glance, at least, this region has done an impressive job of promoting regional cooperation and diffusion of information. However, it is of course also possible that the association was formed around municipalities already having a lot of cooperation. If this is true, the causality runs in the opposite direction.

In order to find out more about what characterizes hubs as transit points, we explore the correlation between the three hub measures introduced above and various municipal characteristics. A first idea is that county seats and larger or more urban municipalities could be important. Such cities might function as regional centers where large companies, authorities, universities, and other organizations are located and where infrastructure is more developed. These features might increase the probability that knowledge diffuses through such municipalities. A second idea is that healthy fiscal conditions or a favorable economic climate might characterize the transit points. Cities like this are perhaps more innovative and outward-looking. Lastly, features of the local population could be important-perhaps transit points have a younger and more educated population?

Table 15.5 provides descriptive statistics of the variables of interest. Log population, inhabitants $/ \mathrm{km}^{2}$ and whether the municipality is a county seat or not are the variables designed to capture the importance of being a large and urban area. Economic climate and fiscal conditions are measured by the unemployment rate and the tax base (in Swedish crowns per inhabitant). Mean age in years and the percentage of the population having a college degree are assumed to capture potentially important citizen characteristics. Table 15.5 displays large variation in all variables. To find out which factors are correlated with high scores on the

\footnotetext{
${ }^{10}$ If hubs were randomly distributed, we would have expected $25 \%$ of the hubs in the Göteborg Region Association of Local Authorities to be hubs.
} 


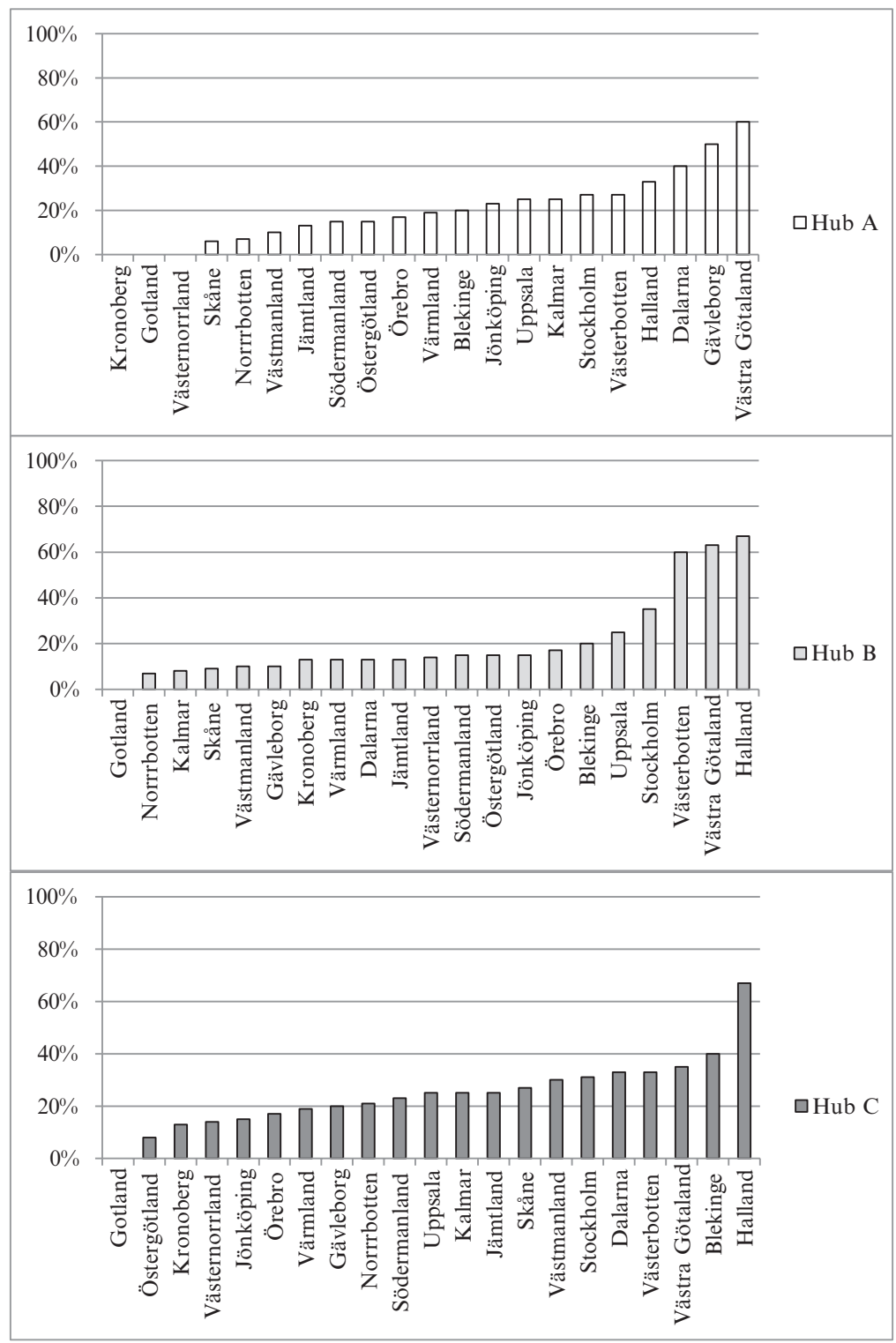

Fig. 15.3 Share of municipalities scoring high ( $>75$ th percentile) on hub measures, by county (Design by authors)

three hub measures, OLS regression is employed. Table 15.6 summarizes the results of this explorative exercise.

A robust and statistically significant finding (at the .05 level) is that county seats (the municipality where the county government resides) are more often learning hubs. This finding applies regardless of which hub measure is employed. County seats score, on average, $0.15-0.22$ of a standard deviation higher on the hub indices 
Table 15.5 Descriptive statistics: Swedish municipalities

\begin{tabular}{lccc}
\hline & Mean & Min & Max \\
\hline Hub A (indegree $\times$ outdegree) & 45.3 & 0.0 & 280.0 \\
Hub B (integration × radiality) & 49.9 & 0.0 & 70.4 \\
Hub C (betweenness centrality) & 907.5 & 0.0 & 11133.4 \\
Log population (number of inhabitants) & 2.9 & 0.9 & 6.7 \\
Inhabitants/km ${ }^{2}$ & 135.0 & 0.2 & 4410.4 \\
County seat (1 =Yes; 0=No) & 0.1 & 0 & 1 \\
Unemployment rate (percent) & 6.3 & 1.8 & 13.8 \\
Tax base (SEK/citizen) & $155,642.1$ & $125,829.0$ & $300,491.0$ \\
Population characteristics & & & \\
Mean age (in years) & 42.8 & 36.3 & 48.5 \\
College degree (percent of population) & 13.0 & 6.6 & 43.8 \\
\hline
\end{tabular}

than other municipalities. Moreover, there is some indication that population size and a young population are positively correlated with being a learning hub. However, these findings are sensitive to the choice of hub measure. For instance, population size is not related to closeness centrality (Hub B) and average age of the municipal citizen is basically not related to betweenness centrality (Hub C). The other background variables included in the analysis do not correlate with the hub measures.

The main conclusion from Table 15.6 is that county seats are important. One way to further investigate this is to examine the E-I index for county seats (using the Girvan-Newman clusters as partitions). Table 15.7 shows the results. The mean E-I index for all municipalities is -.345 , indicating that the ties of most municipalities are local (e.g., within county). By contrast, the average E-I index for county seats is .130 . This means that in contrast with the localism of most municipalities, county seats have on balance more external than internal ties. However, there is also variation among the county seats. For example, the municipalities of Nyköping and Falun are quite insular, whereas Malmö, Visby, and Örebro are quite cosmopolitan.

Taken together, the evidence clearly suggests that county seats are acting as hubs in the learning network of Swedish municipalities. This conclusion is reinforced by looking at the network connecting county seats (Fig. 15.4; note that the figure roughly organizes the county seats geographically). Nyköping and Falun are isolates, but the rest of the county seats are linked together.

\section{Conclusion}

The purpose of this analysis was to better understand how a global learning network emerges from the local learning choices of autonomous Swedish municipalities. We found that the county is a basic structuring property of the global network. Municipalities learn from their near neighbors, especially from neighbors in the 


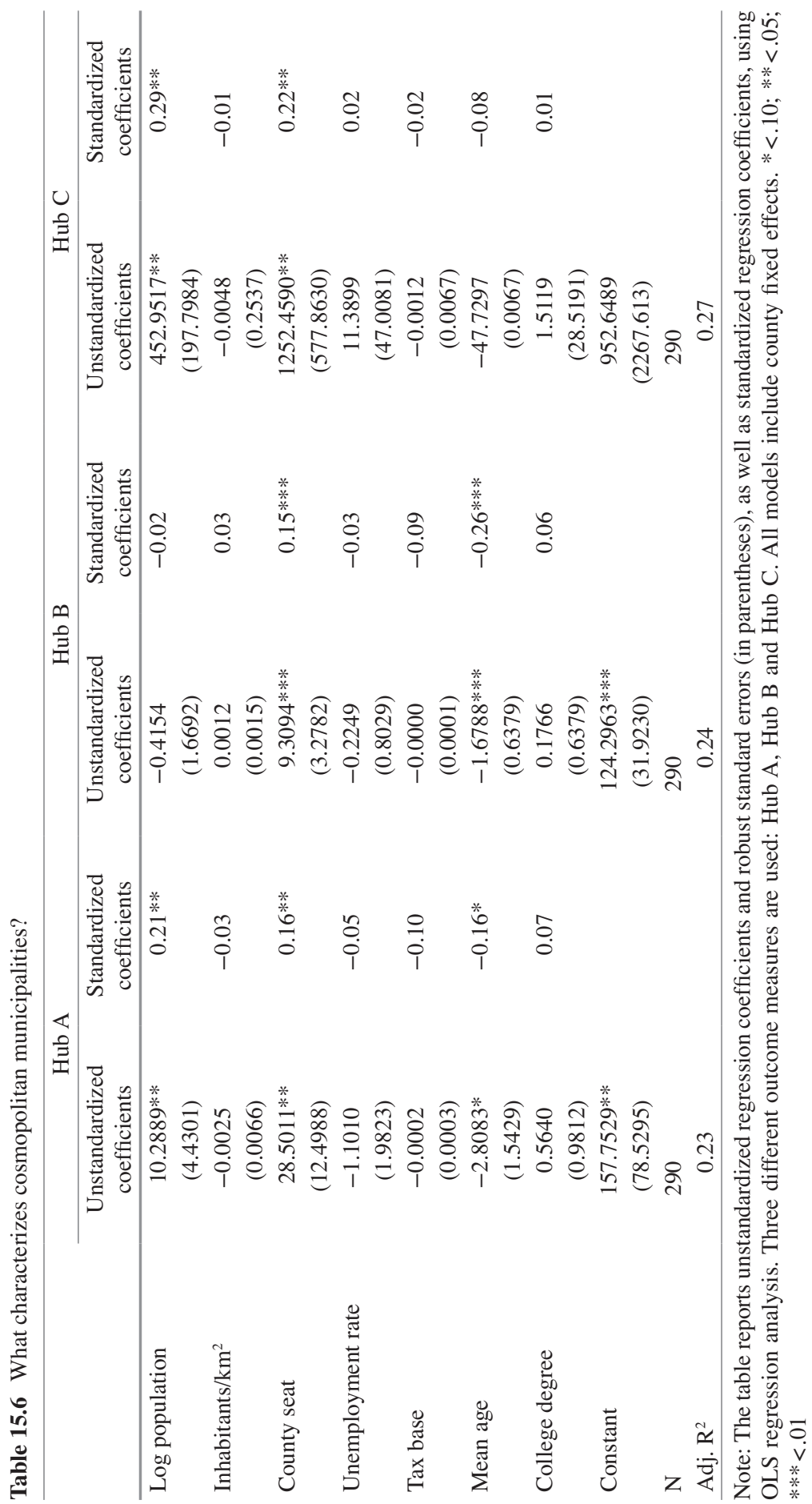


Table 15.7 Internal vs.

External learning in county

\begin{tabular}{llc}
\hline County Seat & County & E-I index \\
\hline Stockholm & Stockholm & .273 \\
Uppsala & Uppsala & .294 \\
Nyköping & Södermanland & -1.00 \\
Linköping & Östergötland & .217 \\
Jonköping & Jönköping & .429 \\
Växjö & Kronoberg & -.077 \\
Kalmar & Kalmar & -.222 \\
Visby & Gotland & .555 \\
Karlskrona & Blekinge & .400 \\
Malmö & Skåne & .579 \\
Halmstad & Halland & .333 \\
Göteborg & Västra Götaland & -.043 \\
Karlstad & Värmland & .176 \\
Örebro & Örebro & .500 \\
Västerås & Västmanland & .355 \\
Falun & Dalarna & -.833 \\
Gävle & Gävleborg & .048 \\
Härnösand & Västernorrland & .167 \\
Östersund & Jämtland & .333 \\
Umeå & Västerbotten & .259 \\
Luleå & Norrbotten & .000 \\
Averages & & \\
All municipalities & & -.345 \\
County seats & & .130 \\
\hline & &
\end{tabular}

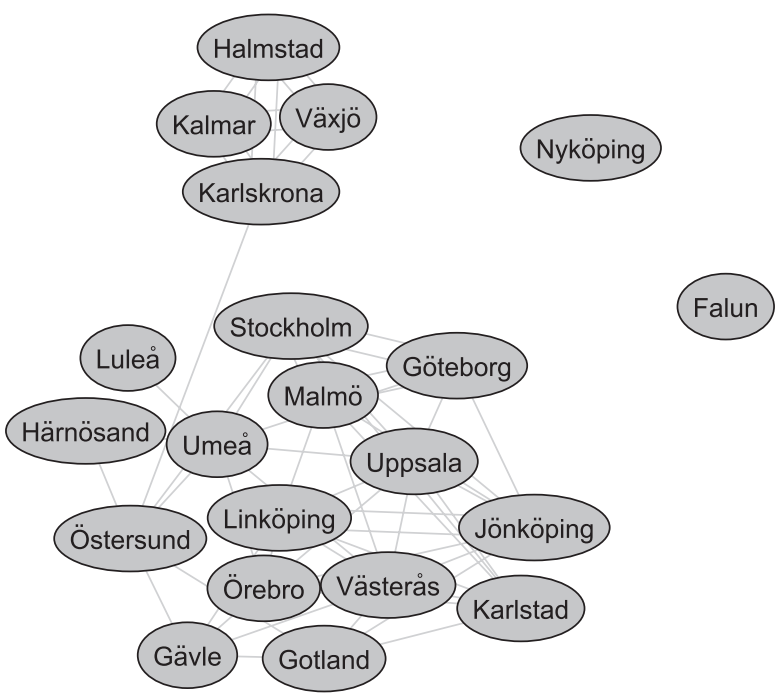

Fig. 15.4 The network of county seats (Design by authors) 
same county. Informal personal connections seem to be the main channel through which municipalities learn from one another.

The high degree of clustering in the municipal learning networks prompted us to examine whether the global network met the criteria for a small-world network, and we have shown that it does. This is important because it suggests that ideas, knowledge, and best practices may diffuse through the network of Swedish municipalities despite the relatively parochial learning patterns of many municipalities. One possible mechanism of integration might be regional agglomeration of networks. Using Markov clustering, we found two very large regions in the global network - a northern coast-Stockholm region and a southern east-west region. These regions extend the pattern of local clustering to the regional level and may be an important basis for nonparochial learning.

Another important mechanism for national integration of municipal learning networks is the role of important network hubs - key transit points in the flow of knowledge. We found that the county seats play this transit-point role for knowledge diffusion. County seats are comparatively well networked outside the county and most of the county seats are linked to one another on a national basis. Hence, although the high clustering of a small-world network is explained by geographic proximity and county, the global integration of this small world works through county seats to a substantial extent. Using county seats as transit points in order to spread best practices more rapidly might therefore be a promising avenue to improve policies.

Interviews suggested that municipalities were quite aware that they learned from geographically proximate neighbors, especially from municipalities within their own county. There may be several reasons why learning is structured this way. Spatially proximate governments often share certain policy-relevant problems, conditions and experiences (Karch, 2007). It is also probably easier to develop a closer relationship with neighboring municipalities; the costs of searching for information from these governments might be lower than looking for information elsewhere (Lundin et al., 2015). Anecdotal evidence from our interviews indicates that municipal bureaucrats tend to circulate between positions in municipalities within counties. This could make it easier to establish the necessary personal connections that, according to our findings, are so important for intermunicipal learning.

There are also other potential explanations for the distinct county pattern that emerges in our analysis. A first possibility is that the role of counties reflects a deep historical legacy. The counties are very close to the old Swedish provinces, whose history reaches back to the seventeenth century. These provinces had a fair degree of political and cultural autonomy and this historical legacy may have structured long-term patterns of intermunicipal interaction. Moreover, in each county, there is a national government authority (Länstyrelsen) acting as a representative of national government to help align local and national policy. Länstyrelsen are also charged with promoting cooperation and working in the interest of the municipalities within the county. This role presumably requires them to work closely with the municipalities in the county. The tendency of municipalities to learn from other municipalities in the same county might be a reflection of the Länstyrelsen's coordinating role. 
Our findings suggest that learning networks are likely to aggregate according to a set of factors that systematically shape learning choices. In the Swedish case, these factors include geographical proximity, personal social relations, urban and regional economic and demographic structure, and political-administrative institutions. Although the important role of geographical proximity and county government are not entirely surprising, we have shown that such factors produce clear global patterns of learning - the small world of Swedish municipalities. This global learning pattern is likely to have important consequences for how knowledge, ideas, and best practices spread to and among Swedish municipalities.

\section{References}

Agranoff, R. (2006). Inside collaborative networks: Ten lessons for public managers. Public Administration Review, 66, 56-65. doi:10.1111/j.1540-6210.2006.00666.x

Amin, A., \& Cohendet, P. (1999). Learning and adaptation in decentralized business networks. Society and Space, 17, 87-104. doi:10.1068/d170087

Arundel, A., \& Hollanders, H. (2011). A taxonomy of innovation: How do public sector agencies innovate? INNO Metrics 2011-2012 report, Brussels, Belgium: European Commission, DG Enterprise. Retrieved June 28, 2015, from http://ec.europa.eu/enterprise/policies/innovation/ files/psi-studies/taxonomy-of-innovation-how_en.pdf

Bäck, H. (2005). Borgmästarens makt [The power of mayors] . Kommunal ekonomi och politik, 9, 7-36. Retrieved May 15, 2015, from http://hdl.handle.net/2077/20675

Bathelt, H., Malmberg, A., \& Maskell, P. (2004). Clusters and knowledge: Local buzz, global pipelines and the process of knowledge creation. Progress in Human Geography, 28, 31-56. doi:10.1191/0309132504ph469oa

Bell, G. G., \& Zaheer, A. (2007). Geography, networks, and knowledge flow. Organization Science, 18, 955-972. doi:10.1287/orsc.1070.0308

Betsill, M. M., \& Bulkeley, H. (2004). Transnational networks and global environmental governance: The cities for climate protection program. International Studies Quarterly, 48, 471-493. doi:10.1111/j.0020-8833.2004.00310.x

Boschma, R. (2005). Proximity and innovation: A critical assessment. Regional studies, 39, 61-74. doi:10.1080/0034340052000320887

Cao, X. (2010). Networks as channels of policy diffusion: Explaining worldwide changes in capital taxation, 1998-2006. International Studies Quarterly, 54, 823-854. doi:10.1111/j.1468-2478.2010.00611.x

Cooke, P., \& Morgan, K. (1993). The network paradigm: New departures in corporate and regional development. Environment and Planning D, 11, 543-564. doi:10.1068/d110543

Cowan, R., \& Jonard, N. (2004). Network structure and the diffusion of knowledge. Journal of Economic Dynamics and Control, 28, 1557-1575. doi:10.1016/j.jedc.2003.04.002

Davis, G. F. (1991). Agents without principles? The spread of the poison pill through the intercorporate network. Administrative Science Quarterly, 36, 583-613. doi:10.2307/2393275

Fleming, L., King, C., \& Juda, A. I. (2007). Small worlds and regional innovation. Organization Science, 18, 938-954. doi:10.1287/orsc.1070.0289

Freeman, L. C. (1977). A set of measures of centrality based on betweenness. Sociometry, 40, 35-41. doi:10.2307/3033543

Freeman, R. (2008). Learning in public policy. In R. E. Goodin, M. Moran, \& M. Rein (Eds.), The Oxford Handbook of Public Policy (pp. 367-388). Oxford: University Press. doi:10.1093/oxfo $\mathrm{rdhb} / 9780199548453.003 .0017$ 
Girvan, M., \& Newman, M. E. J. (2002). Community structure in social and biological networks. Proceedings of the National Academy of Sciences, 99, 7821-7826. doi:10.1073/pnas.122653799

Glückler, J. (2013). Knowledge, networks and space: Connectivity and the problem of non-interactive learning. Regional Studies, 47, 880-894. doi:10.1080/00343404.2013.779659

Goldsmith, S., \& Eggers, W. D. (2004). Governing by network: The new shape of the public sector. Washington: Brookings Institution Press.

Granovetter, M. S. (1973). The strength of weak ties. American Journal of Sociology, 78, $1360-1380$.

Gray, V. (1973). Innovation in the states: A diffusion study. The American Political Science Review, 67, 1174-1185. doi:10.2307/1956539

Gren, J. (2002). New regionalism and West Sweden: The factors of change in the regionalism paradigm. Regional \& Federal Studies, 12, 79-101. doi:10.1080/714004766

Hedström, P., Sandell, R., \& Stern, C. (2000). Mesolevel networks and the diffusion of social movements: The case of the Swedish social democratic party. American Journal of Sociology, $106,145-172$.

Jacobs, J. M. (2012). Urban geographies I: Still thinking cities relationally. Progress in Human Geography, 36, 412-422. doi:10.1177/0309132511421715

Karch, A. (2007). Emerging issues and future directions in state policy diffusion research. State Politics and Policy Quarterly, 7, 54-80. doi:10.1177/153244000700700104

Kraatz, M. S. (1998). Learning by association? Interorganizational networks and adaptation to environmental change. Academy of Management Journal, 41, 621-643. doi:10.2307/256961

Krause, R. M. (2011). Policy innovation, intergovernmental relations, and the adoption of climate protection initiatives by US cities. Journal of Urban Affairs, 33, 45-60. doi:10.1111/j.1467-9906.2010.00510.x

Lee, C. K., \& Strang, D. (2006). The international diffusion of public-sector downsizing: Network emulation and theory-driven learning. International Organization, 60, 883-909. doi:10.1017/ S0020818306060292

Lee, T., \& Van De Meene, S. (2012). Who teaches and who learns? Policy learning through the C40 cities climate network. Policy Sciences, 45, 199-220. doi:10.1007/s11077-112-9159-5

Lidström, A. (2011, November). The limits of rational choice: Localism and city-regionalism in two Swedish city-regions. Paper prepared for XX Nordiska kommunforskarkonferensen, Göteborg. Retrieved May 27, 2015, from http://www.pol.gu.se/digitalAssets/1350/1350051_ the-limits-of-rational-choice-anders-lidstr--m.pdf

Lundin, M., Öberg, P., \& Josefsson, C. (2015). Learning from Success: When Can Local Government Serve as a Role Model to Others? Public Administration, 93 (3), 733-752.

Marsden, G., Frick, K. T., May, A. D., \& Deakin, E. (2011). How do cities approach policy innovation and policy learning? A study of 30 policies in Northern Europe and North America. Transport Policy, 18, 501-512. doi:10.1016/j.tranpol.2010.10.006

Maskell, P. (2014). Accessing remote knowledge - the roles of trade fairs, pipelines, crowdsourcing and listening posts. Journal of Economic Geography, 14, 883-902. doi:10.1093/jeg/lbu002

McCann, E. (2011). Urban policy mobilities and global circuits of knowledge: Toward a research agenda. Annals of the Association of American Geographers, 101, 107-130. doi:10.1080/0004 5608.2010.520219

Meseguer, C. (2005). Policy learning, policy diffusion, and the making of a new order. Annals of the American Academy of Political and Social Science, 598, 67-82. doi: $10.1177 / 0002716204272372$

Mintrom, M., \& Vergari, S. (1998). Policy networks and innovation diffusion: The case of state education reforms. The Journal of Politics, 60, 126-148. doi:10.2307/2648004

Owen-Smith, J., \& Powell, W. W. (2004). Knowledge networks as channels and conduits: The effects of spillovers in the Boston biotechnology community. Organization Science, 15, 5-21. doi:10.1287/orsc. 1030.0054

Powell, W. W., Koput, K. W., \& Smith-Doerr, L. (1996). Interorganizational collaboration and the locus of innovation: Networks of learning in biotechnology. Administrative Science Quarterly, 41, 116-145. doi:10.2307/2393988 
Saxenian, A. (1996). Regional advantage: Culture and competition in Silicon Valley and Route 128. Cambridge, MA: Harvard University Press.

Sellers, J. M., \& Lidström. A. (2007). Decentralization, local government, and the welfare state. Governance, 20, 609-632. doi:10.1111/j.1468-0491.2007.00374.x

Shipan, C. R., \& Volden, C. (2012). Policy diffusion: Seven lessons for scholars and practitioners. Public Administration Review, 72, 788-796. doi:10.1111/j.1540-6210.2012.02610.x

Slaughter, A. M. (2009). A new world order (2nd ed.). Princeton: University Press. (Original work published 2004)

Stone, D. (2004). Transfer agents and global networks in the "transnationalization" of policy. Journal of European Public Policy, 11, 545-566. doi:10.1080/13501760410001694291

Sveriges Kommuner och Landting (2014, March 28). Swedish Association of Local Authorities and Regions. Retrieved March 28, 2014, from http://english.skl.se/municipalities_county_councils_ and_regions

Trydegård, G.-B., \& Thorslund, M. (2010). One uniform welfare state or a multitude of welfare municipalities? The evolution of local variation in Swedish elder care. Social Policy \& Administration, 44, 495-511. doi:10.1111/j.1467-9515.2010.00725.x

Uzzi, B., Amaral, L. A., \& Reed-Tsochas, F. (2007). Small-world networks and management science research: A review. European Management Review, 4, 77-91. doi:10.1057/palgrave. emr. 1500078

Valente, T. W., \& Foreman, R. K. (1998). Integration and radiality: Measuring the extent of an individual's connectedness and reachability in a network. Social Networks, 20, 89-105. doi:10.1016/S0378-8733(97)00007-5

van Dongen, S. (2008). Graph clustering via a discrete uncoupling process. SIAM Journal on Matrix Analysis and Applications, 30, 121-141. doi:10.1137/040608635

Volden, C. (2006). States as policy laboratories: Emulating success in the children's health insurance program. American Journal of Political Science, 50, 294-312. doi:10.1111/j.1540-5907.2006.00185.x

Watts, D. J. (1999). Small worlds: The dynamics of networks between order and randomness. Princeton: University Press.

Open Access This chapter is distributed under the terms of the Creative Commons Attribution 4.0 International License (http://creativecommons.org/licenses/by/4.0/), which permits use, duplication, adaptation, distribution and reproduction in any medium or format, as long as you give appropriate credit to the original author(s) and the source, provide a link to the Creative Commons license and indicate if changes were made.

The images or other third party material in this chapter are included in the work's Creative Commons license, unless indicated otherwise in the credit line; if such material is not included in the work's Creative Commons license and the respective action is not permitted by statutory regulation, users will need to obtain permission from the license holder to duplicate, adapt or reproduce the material.

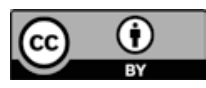

